\title{
ELEMENTS OF PSYCHOLOGICAL THEORY OF MELODY.
}

\author{
BY MAX MEYER, PH.D., \\ Honorary Fellow in Psychology at Clark University.
}

In the following pages I intend simply to describe musical facts by laws, not to explain their existence. I have not been fortunate enough to discover the cause of consonance, and therefore readers who are interested in explanations only may lay aside this paper at once.

There are plenty of books on musical theory, written by professional musicians, physicists, physiologists, psychologists and philosophers. But when one has studied them throughout in order to find psychological laws one must confess finally that he has not found any. The only investigator in psychological literature who hit the right path is Th. Lipps. However, after having followed this path a short distance, he turned into the common path, more conspicuous because more frequented, which crosses the right path many times, but does not lead, as that one does, to the top of the mountain, but after devious windings leads back again to the starting point. In all the bulky books of musicians on musical theory I have sought in vain for scientific laws. No doubt, there are laws in those books, but they are not scientific, as they are true only in a limited number of special cases and contradict the rest.

The wrong path, much frequented, which inevitably leads back to the starting point, is the adoption of the theory that the basis of all music is the so-called diatonic scale, represented by the numbers $24,27,30,32,36,40,45,48$.

From this theory arise all the errors which prohibit the development of a scientific theory of music. The adoption of that theory prevented Lipps from carrying his investigations farther. The same mistake prevented Gurney (in his very good book 'The Power of Sound') from solving the problem, which he 
clearly shows as unsolved, and led him to the conclusion that it was 'hopeless to think of penetrating music in detail,' because he had found no way himself. Still I do not understand why he undertook to write a book of 600 pages on music while believing that it was " hopeless to think of

\section{Untwisting all the chains that tie The hidden soul of Harmony."}

The only right conclusion is that the way he followed was the wrong one. Unable to explain the real existence in music of those notes which have no theoretic existence in the diatonic scale, he attempted to explain them in a manner that has become quite common in recent years, assuming that the place of such notes in a musical form, relationship being in abeyance, was wholly due to close propinquity.

The consequence of this theory would be that the tones corresponding to the numbers $10, I I, I 2, I I$, IO would result in the formation of a melody, ro and 12 being connected by relationship, II with either ro and I 2 by propinquity. Should the propinquity be not close enough, we might take the numbers 30 , $3^{1}, 3^{6}, 31,3^{\circ}$. To listen only once to such a tune is quite sufficient to be convinced of the perverseness of that theory. No melody can be formed by the help of propinquity. No tone that appears in music is really without relationship. The fact that some one-without having sought for it-has not discovered any relationship between certain notes, does not prove that relationship is in abeyance.

Yet Gurney only follows here Helmholtz, who has not found any relationship between such tones. ${ }^{1}$ He says : " "It is nothing but a step intercalated between two tones, which has no relation to the scale, and only serves to render its discontinuous progression more like the gliding motion of natural speech, or weeping or howling." Now, I have not the least doubt that Helmholtz would really have been delighted to dispense with music 'like the gliding motion of natural speech, or weeping or howling.'

\footnotetext{
1 'Accidentals' these tones are called by the theorists. But in a real work of art there is nothing accidental.
}

2 Sensations of Tone, $2 d$ ed., p. $35^{2}$ b. 
Such is the music of cats at midnight, not of mankind. So I need not add anything to this argument.

Stumpf in his most recent publication on Consonance and Dissonance ${ }^{1}$ shows that he believes in the dogma of the diatonic scale as strongly as anyone else.

My investigations into musical theory led me to the conclusion, that one of the chief errors is the exclusion of the number 7 . Herzogenberg, ${ }^{2}$ indeed, tried to introduce the 7 into the theory of music. But just where he thought the 7 to be in place, is this number obviously in the wrong place. My investigations into the question as to whether the 7 really plays a part in music, had already led me to final conclusions, when recently I found, looking by chance at the English translation of Helmholtz's 'Tonempfindungen,' that similar conclusions had been drawn half a century before by $\mathrm{H}$. W. Poole, ${ }^{3}$ then an organ builder in Worcester, Mass. In the first two German editions of the ' Tonempfindungen' Poole is not mentioned at all, in the third he is mentioned only as the inventor of a new keyboard, not as the author of a musical theory. Ellis only in his translation of the 'Tonempfindungen' thought Poole's theory at least worth mentioning, although he does not recognize it as true. However imperfect and inconsistent Poole's theory, as stated in his paper, appears, he deserves the credit of having first found one of the most influential obstacles to the progress of musical theory. He seems to me to have made a mistake in so far as he attempted to introduce at once his immature theory into musical practice and spent his time in inventing new keyboards, which are very interesting indeed, but are of little value in improving or developing the theory.

The so-called diatonic scale, which is the basis of all discussions in Helmholtz's 'Tonempfindungen,' was introduced into the modern theory of music by Zarlino in $155^{8}$. It was accepted by Rameau in his 'Traité de l'Harmonie,' 1721. According to Rameau (and Helmholtz) no numbers play any part in music but $I, 2,3,4,5$ and 6 . This is certainly not a law

'Beiträge zur Akustik und Musikwissenschaft, 1.

Vierteljahrsschrift für Musikwissenschaft, vol. ro, pp. I33-145.

- Silliman's American Journal of A rts and Sciences, 1850, vol. 9, pp. 68-83, 199-216. 
derived inductively from observed facts, but a dogma, because one may, as Poole rightly states, very easily observe that the 7 acts psychologically in a way corresponding to the action of 2 , 3 and 5 , whereas, indeed, with other prime numbers, as II, ${ }_{3}$, etc., this is not the case.

Rameau built up the scale in the following way: He started from a certain pitch called tonic, to which in the scale he attributed the number 24. Now, because the tones of the intervals $2: 3$ and $3: 4$ besides the octave $I: 2$ have the closest relationship, he added to 24 the numbers 32 and $36,24: 36=2: 3,24: 32=$ $3: 4$. We shall later see that the mistake here made by him was his starting from mere consideration of harmony, without noticing that in melody the form of succession, the way in which the tones follow each other, brings into existence quite a new factor of the greatest importance. If Rameau had considered this, he would have found that the tonic of a melody can never be represented by the number 24 , which contains 3 . The same error has entered all theories-as far as I know-up to this time. Even Poole, although he detected the possibility of using the 7 , because of his use of harmony as a starting point did not see that it is simply impossible to represent the tonic by a number containing 3 , but stated that the old theory in very many cases was right, whereas really there is not one single case where that theory cannot be demonstrated to be wrong.

We saw that Rameau concluded the numbers $24,3^{2}$ and $3^{6}$ to be the most important in his scale. Now, since $24: 30: 3^{6}$ and $32: 40: 48$ and $36: 45: 54$ each represent the chord $4: 5: 6$, he built up his complete scale out of those numbers, only using instead of 54 the half $27: 24,27,30,32,36,40,45,48 .^{1}$

From this scale he derived another scale for the so-called music in 'minor' by beginning from 40 and multiplying the first numbers of the 'major' scale by $2: 40,45,48,54,60,64$, 72,80 .

'Rameau's 'explanation' of the esthetic effect of the relation of pitches by the mere physical fact, that sounding bodies usually produce, not a single pitch, but several simultaneously (partial tones), does not concern us here any more than Helmholtz's 'explanation' of the same effect by 'identical partial tones' $: x$, because these explanatlons do not explain anything but contradict almost more tucts than they confirm; 2, because our task in the present paper is only to describe observable facts by laws, but not to deal with hypotheses. 
But neither Rameau, nor before him Zarlino, nor after him Helmholtz and his followers have thought it necessary to tell their readers what facts observable in melody justified the use of that series of numbers as the basis of a theory of music in general-of melody as well as of harmony. We shall in the following start from melody, because melody is the only essential of music.

Comparing different melodies with the so-called diatonic scale, we notice that some melodies contain fewer, others more notes than that scale. How do these facts agree with the theory that the diatonic scale is the basis of all music? To this question Helmholtz answers : in the first case the composer has not made use of every note, in the second he has added some notes in order to render the music more like howling. The only answer I know is: to base any music on the diatonic scale is a fancy.

For a long time the tempered scale of twelve equal intervals within the octave has been used in music. Rameau, who recommends this scale for practical purposes, claims that any interval of two successive notes in real music, equal to threetwelfths of the octave, e.g., g-a on the piano, has to be regarded theoretically as the interval $5: 6$, any interval of two successive notes equal to four-twelfths, e. $g ., a-c \#$ on the piano, as the interval $4: 5$, etc., although there are slight differences. The result of this assumption has been the theory that music is made up out of intervals, $i . e$, that the intervals between the notes immediately following each other are the essentials of music, causing the asthetic effect. This theory is supported even by Helmholtz, although it obviously contradicts his theory of the diatonic scale and his doctrine of what he calls 'just intonation.' An example of this theory of intervals is to be found in Helmholtz's statement, that the æsthetic beauty of a melody depends on the number of Thirds and Sixths which it contains, a statement that lacks any foundation, as Gurney has demonstrated. ${ }^{k}$ We shall see that music is made up, not of intervals, but of notes and that the relative pitches indeed cause the rsthetic effect, but not only the intervals of every two immediately following pitches.

1 Pover of Sound, p. $3_{4}^{8}$ 
There can be no doubt that the tempered scale cannot be made the basis of a theory of music, that theoretic conclusions drawn from considerations regarding the intervals of the tempered scale have no scientific foundation. A scientific theory of music can only be a theory describing the laws of music performed in just intonation, but in just intonation that really is to be called 'just,' not in that seemingly just intonation of Helmholtz, which-as can be proved by experiment-does not deserve this name.

\section{The Asthetic Laws of Melodies, which CONTAIN ONLY Two Different Notes.}

When we hear successively two tones, the vibration rates of which are to each other as $2: 3$, or briefly speaking, the tones 2 and 3 , we notice something not describable, which I shall call the relationship of these tones. ${ }^{1}$ To understand what is meant hereby, the reader may listen to the successive tones 7 and $I I$ or II and 10, in which cases he will notice that the two tones have no relation at all to each other. We may describe these same facts in still another way, saying that in the first case $(2-3)$ the two ${ }^{2}$ tones form a melody, whereas in the other case $(7-I I)$ they do not. This expression means the same thing, although different words are used.

Beside the relationship, the hearer will observe in the case of 2 and 3 something else, namely, that after hearing 2 and then 3 , he wishes to go back to $2, i$. e., to hear 2 once more. On the other hand, when we hear 3 at first and after that 2 , we do not wish to hear 3 once more. If 3 and 2 are repeated several times in order to prolong the melody built up out of these tones, we are satisfied in the case where the melody ends with 2, dissatisfied in the case where the melody ends with 3 . Save in a few instances, where a peculiar psychological effect is aimed at, no melody that contains 2 can end with another tone but 2 .

In the following I shall try to describe the facts in a language as plain as possible, avoiding all dubious terms like 'fusion' ('Verschmelzung'), all flowery, but meaningless phrases, so common in musical æsthetics, and all the barbarous terms of the ancient and medixval and even modern theorists, which are a mere burden to memory, without having any scientific value.

For the sake of simplicity we consider at first melodies of two different notes only. 
In the case of the tones 3 and 4 the melody must end with 4 , not with 3 ; in the case of 4 and 5 with 4,5 and 8 with 8,7 and 8 with 8,4 and 9 with 4,15 and 16 with $16 ; i . e$., the general law is: "one of the tones being a pure power of 2 , we wish to have this tone at the end of our succession of related tones, our melody."1

When we hear a melody built up of the successive tones 3 and 5 or 5 and 7 , we observe a relationship similar to that of the cases above, but we notice that it does not make any difference whether we hear, $e . g ., 3$ first and then 5 or 5 first and then 3 . In neither case do we wish to hear the first tone once more or not once more ; or better : such a wish, if any, is not caused by the particular relationship of these tones. This psychological effect is indeed restricted to the powers of 2 (including $I=2^{\circ}$ ).

That no relationship at all is to be observed with tones represented by the prime numbers II, I3, I7, I9, etc., leads to the conclusion that only tones represented by the prime numbers $I$, $2,3,5,7$ and their composites possess that psychological property. That the 7 cannot be excluded in the case of two different notes, does not, of course, decide the question whether in the case of more complicated melodies-as in real music-the 7 really is excluded or not. This question can be answered by observation only. So much is certain, that there is no reason for excluding the 7 from the theory of music a priori. We shall see later that there are very few melodies indeed which do not contain the 7 .

The relationship, which we observe, is closer in some cases than in others; e.g., very close with the tones represented by the numbers $I$ and 2 , or 3 and 8 , less close with the tones 3 and

${ }^{1}$ Lipps (Psychologische Studien, Heidelberg, 1885), who describes these facts in a similar, although not in the same, way, has tried to explain why these facts are facts by the hypothesis, that any sensation of tone is not really a continuous sensation, but a series of short sensations interrupted by short empty times. These single short sensations, each corresponding to one single vibration, are to be observed, according to Lipps, only in the case of very low tones. I have shown in my paper, 'Ueber die Rauhigkeit tiefer Töne' (Zeitschrift fiur Psychologie, 13, p. 75), that there is not the slightest foundation for such a hypothesis. Doubtless, regarding explanations of the facts above stated, the progress of the physiology of the nervous system in the future will bring us in 2 moment farther than any speculation is able to do. 
5 , or 5 and 7 , or 15 and 16 . I have tried to bring the different relationships into a series. It seems to me, that the order of relationship within one octave is the following: $1-2,2-3,4-5$, $5-6,4-7,6-7,8-9,15-16,5-7,5-9$. Whether there is a slight degree of relationship in the cases of $7-9$ and $1_{4}-15$, or no relationship at all, I do not venture to decide. Transpositions by octaves do not, according to my observations, cause any difference, so that the relationship of $I-3$ is of the same rank as that of $2-3$, the relationship of $3-5$ of the same rank as that of $5-6$. I do not assert that the series above represents quite an accurate order of the relationships. However, whether the series is a little more or less accurate, is of very little importance for the subsequent investigations. I will emphasize further, that when I speak of the relationship of two successive tones, the order of succession of the two tones in the melody is not regarded at all.

Similarly, we observe in those cases where one of the two tones is represented by a pure power of 2 , that our wish to have this tone at the end of the melody is much stronger in some cases than in others; $e . g$., very strong with tones represented by the numbers 3 and 2 , or 3 and 4 , or 5 and 4 , less strong with tones represented by the numbers 7 and 8 , or 9 and 8 . However we may omit here an accurate determination of the place that would appertain to each ratio in a complete series, because this does not appear to be of considerable importance for our present investigations.

One question of this kind we may still consider, namely, whether in the case of the octave, where the tones are represented by the numbers $I$ and 2 , the psychological effect of the melody's being closed by $I$ is different from that when the melody is closed by 2. Lipps ${ }^{2}$ asserts that of the two tones I

I Psychologische Studien, p. I32: "In jedem Ton ist der Rbythmus seiner tieferen Octave, nicht der der höheren, vollständig enthalten. Ist ein Ton gegeben, so bedarf es zum Vollzug der Empindung eines nachfolgenden am eine Octave höheren Tones noch der selbständigen $Z$ weitheilung des durch den gegebenen Ton vorgezeichneten Rhythmus. Diese Zweitheilung ist, wie oben gessgt, die einfachste rhythmische Leistung. Immerhin ist sie eine Leistung. Dagegen wird unserem Empfindungs-vermögen gar michts rhythmisch Nenes zugemathet, wenn die tiefere Octave folgt. Darnach muas der Octavenschritt wan oben nach unten in geringerem Grade als der Fortschritt zu etwas Nenern erscheinen und in höherem Grade den Eindruck des sich in sich Beruhigenden, 
and 2 , we prefer to have $I$ at the end of the melody. I could not convince myself of the truth of Lipps's assertion and am inclined to believe that he was deceived when he made this observation, either by having in mind at the same time a certain complicated melody which contains two tonics, but closes on the tonic below, or by-what is less probable in this case, but happens very easily in psychological observations-yielding to his own theory, based on the hypothesis above mentioned, which indeed leads to such a conclusion. I have to confess myself that, if I exclude all psychological effects of tones other than I and 2, I cannot detect any difference, whether $I$ is at the end or 2. This justifies my regarding I simply as a power of 2 .

\section{The Complete Musical Scale.}

The complete musical scale is the series of all tones, which may occur in one melody, however complex this may be. As soon as we know the æsthetic laws of melodies, which contain only two different notes, it is very easy to construe this scale. Suppose a melody begins with the tone 5 , followed by 3 . Now we know that if it results in a melody at all, the tone 3 can be followed only by a tone that is related either to 3 or perhaps to 5 or, if not related to either 3 or 5 , perhaps to a further tone that is itself related to either 3 or 5 . It is impossible, therefore, that the third tone in this melody should be, $\varepsilon . g$. , I9 or 33 , because neither I9 nor 33 fulfills any of these three conditions. So the third tone can only be a composite of powers of $2,3,5$ and $7 ;$ e.g., 45 , which is related to 5 as well as to 3 ; or 75 , which is related to 5 ; or $\mathrm{I} 35$, if this is followed, e. $g$., by 9 , which is related to 135 as well as to 3 and 5 . Generally speaking, since relationship of two successive tones is observed only in the cases where the tones are represented by composites of $2,3,5$ and 7 , we have to draw the conclusion, that a complete musical scale cannot contain any numbers except powers of 2,3 , 5 and 7 and their composites. Still, whereas in the case of only two different notes the numbers representing possible tones are

also endgültig Abschliessenden machen, als der von unten nach oben. Dass es in Wirklichkeit so ist, kann nicht bezweifelt werden." I regret that from my own observations I am compelled to doubt this. 
-according to observation-restricted to the numbers of certain ratios enumerated in the above series of relationships, there can of course be no restriction if the melody can contain an unlimited number of different notes. I. e., the complete musical scale is represented by the infinite series of all composites of the pozvers of $2,3,5$ and 7 . We find the beginning of this series in the table on page $25 \mathrm{I}$, if we omit the numbers of the lowest line, save $2^{\circ}$, and read the table from the bottom to the top.

Actually, of course, no music will ever make use of an infinite number of different notes; if for no other reason than that the life of a man would be too short for such a performance. We need not, therefore, continue the series farther than actually existing music requires. I have found the series to suffice when continued up to Io24. Besides, in the table, I have omitted of 5 all higher powers than $5^{3}$ and of 7 all higher powers than 7 itself, because I have found no case where these omitted powers of 5 and 7 are used. This is interesting when compared with the fact that of 3 much higher powers are used, and that $9=3^{2}$ appears even in ratios that represent direct relationship, and that of 2 all the powers are of absolutely equal value with respect to relationship. 
Complete Musical Scale (New Theory).

\begin{tabular}{|c|c|c|c|c|c|c|c|c|c|c|c|c|c|c|c|c|c|c|c|c|c|c|c|c|c|c|c|c|}
\hline \multicolumn{2}{|c|}{$\begin{array}{c}c \# \\
542.4\end{array}$} & \multicolumn{3}{|c|}{$\begin{array}{c}d \\
574.7 \\
\end{array}$} & \multirow{2}{*}{$\begin{array}{c}\begin{array}{c}\mathrm{d} \\
608.9 \\
- \\
25 \\
3\end{array} \\
\end{array}$} & \multicolumn{3}{|c|}{$\begin{array}{c}e \\
645 \cdot I \\
\end{array}$} & \multicolumn{2}{|c|}{$\begin{array}{c}f \\
683.4 \\
\end{array}$} & \multicolumn{3}{|c|}{$\begin{array}{c}f \# \\
724 . I \\
\end{array}$} & \multicolumn{3}{|c|}{$\underset{767 \cdot 1}{g}$} & \multicolumn{2}{|c|}{$\begin{array}{c}g \# \\
812.8 \\
\end{array}$} & \multicolumn{2}{|c|}{$\stackrel{a}{861.1}$} & \multicolumn{2}{|c|}{$\begin{array}{c}\text { a\# } \\
912.3\end{array}$} & \multicolumn{3}{|c|}{$\begin{array}{r}b \\
966.5 \\
\end{array}$} & \multicolumn{3}{|c|}{$\begin{array}{c}c \\
1024.0\end{array}$} \\
\hline $\begin{array}{r}7 \\
25 \\
3 \\
\end{array}$ & $\begin{array}{r}- \\
27 \\
\end{array}$ & $\begin{array}{r}7 \\
5 \\
\end{array}$ & $\frac{7}{81}$ & $\frac{7}{9}$ & & $\begin{array}{l}7 \\
5 \\
9 \\
\end{array}$ & $\frac{5}{5}$ & $\overline{81}$ & $\frac{7}{3}$ & $\mid \begin{array}{l}- \\
25 \\
27\end{array}$ & $\begin{array}{r}7 \\
25 \\
-\end{array}$ & \begin{tabular}{l|}
5 \\
9
\end{tabular} & $\frac{-}{729}$ & $\begin{array}{c}- \\
125 \\
3\end{array}$ & $\frac{7}{27}$ & $\frac{-}{3}$ & $\overline{25}$ & $\mid \begin{array}{r}-5 \\
81\end{array}$ & $\begin{array}{r}7 \\
\therefore 5 \\
3\end{array}$ & $\bar{z}$ & $\frac{7}{-}$ & $\begin{array}{r}-25 \\
9\end{array}$ & $\begin{array}{r}7 \\
5 \\
27\end{array}$ & $\begin{array}{l}\overline{5} \\
3\end{array}$ & $\frac{-}{243}$ & I25 & $\frac{7}{9}$ & $=$ \\
\hline 525 & $\begin{array}{l}540 \\
270 \\
135\end{array}$ & $\begin{array}{r}560 \\
280 \\
140 \\
70 \\
35\end{array}$ & 567 & $\begin{array}{r}576 \\
288 \\
144 \\
72 \\
36 \\
18 \\
9\end{array}$ & $\begin{array}{r}600 \\
300 \\
150 \\
75\end{array}$ & $\left|\begin{array}{l}630 \\
315\end{array}\right|$ & $\mid \begin{array}{r}640 \\
320 \\
160 \\
80 \\
40 \\
20 \\
10 \\
5\end{array}$ & $\begin{array}{r}648 \\
324 \\
162 \\
81\end{array}$ & $\mid \begin{array}{r}672 \\
336 \\
168 \\
84 \\
42 \\
2 I\end{array}$ & & $\begin{array}{l}700 \\
350 \\
175\end{array}$ & $\begin{array}{r}720 \\
360 \\
180 \\
90 \\
45\end{array}$ & 729 & $\begin{array}{l}750 \\
375\end{array}$ & $\begin{array}{l}756 \\
378 \\
189\end{array}$ & $\begin{array}{r}768 \\
384 \\
192 \\
96 \\
48 \\
24 \\
12 \\
6 \\
3\end{array}$ & $\begin{array}{r}800 \\
400 \\
200 \\
100 \\
50 \\
25\end{array}$ & $\begin{array}{l}810 \\
405\end{array}$ & $\begin{array}{l}840 \\
420 \\
210 \\
105\end{array}$ & \begin{tabular}{|r|}
864 \\
432 \\
216 \\
108 \\
54 \\
27
\end{tabular} & $\mid \begin{array}{r}896 \\
448 \\
224 \\
112 \\
56 \\
28 \\
14 \\
7\end{array}$ & $\begin{array}{l}900 \\
450 \\
225\end{array}$ & 945 & \begin{tabular}{|r|}
960 \\
480 \\
240 \\
120 \\
60 \\
30 \\
15
\end{tabular} & $\begin{array}{l}972 \\
486 \\
243\end{array}$ & \begin{tabular}{|r|}
1000 \\
500 \\
250 \\
125
\end{tabular} & $\mid \begin{array}{r}1008 \\
504 \\
252 \\
126 \\
63\end{array}$ & $\begin{array}{r}1024 \\
512 \\
256 \\
128 \\
64 \\
32 \\
16 \\
8 \\
4 \\
2 \\
2^{\circ}\end{array}$ \\
\hline
\end{tabular}


The numbers in the table, which of course represent relative pitch, are brought into connection with an absolute pitch by arbitrarily calling $c$ the pure powers of 2 . In the line below the musical names are the numbers which-compared with the octave 5 I 2 to 1024 in the complete scale-represent the pitches corresponding to the system of $\mathrm{x} 2$ notes in equal intervals within the octave, a system that is generally used with instruments of unalterable pitches, as on the piano. Below this line we see the powers of 3,5 and 7 , of which the numbers of each column are composed.

In the following I shall make use of a simplified method of numeration. All pure powers of 2 , as $1,2,4,8,16,32$, etc., will be represented equally by 2 . All composite numbers containing a pozver of 2 will be represented without the power of 2. So I always shall write simply 5 instead of any of the numbers $5,10,20,40$, etc., 9 instead of $9,18,36,72$, etc., 27 instead of, e. $g ., 432,21$ instead of, e. g., 336, etc. The advantage of this method will show itself. ${ }^{\prime}$ The bottom line of the table contains the numbers which are used to represent in my theory any of those numbers which are different only by powers of $2, i$. e., any of the numbers of the same column.

\section{Analysis of Complex Melodies.}

We are now sufficiently prepared to pass on to the analysis of complex melodies. By 'complex melodies' I mean melodies which contain tones not related to each other, or, better, tones related to each other not directly, but by mediation of a third tone, so that, as we shall see, the melody must theoretically be dissolved into partial melodies. We shall analyze a number of well-known melodies and derive from them inductively the laws of construction of complex melodies.

Our first task must be, to determine exactly the relative pitches which the composer meant in a certain melody. The

I I ask the reader, if he wishes to understand my theory, to bear in mind that according to this numeration $9: 3$ is identical with $3: 2$, although arithmetically $9: 3=3: x$. But in my theory it is necessary to regard $I$ as a power of 2 and to represent 1 -as all powers of 2-by the number 2 . Just so is $75:$ is (which in absolute numbers may represent, e.g., $150: 240$ or $75: 30$ ) identical with $5: 2$. 
common musical notation, the historical development of which must be understood, does not give the pitches exactly, but approximately. In order to determine the pitches meant by the composer, we must have an instrument that gives all possible pitches, so that we only have to choose among them. Those organs which have hitherto been built by Helmholtz and others in order to compare Helmholtz's 'just intonation' with ' tempered' intonation, cannot serve our purpose, because they do not contain all possible pitches, as represented in our table of the complete scale. By the aid of Clark University I have been able to construct a reed organ that gives exactly the pitches of the highest four octaves $(64-1024)$ in the table. The absolute pitch of this organ has been arbitrarily chosen and is identical with the numbers in the table representing the relative pitches, so that the lowest reed gives $6_{4}$ (complete) vibrations in a second.

By the help of this organ it is, in most cases, very easy to determine what pitch is meant by the composer. In very rare cases only is there doubt which of two (or more) possible pitches produces the better æsthetic effect. The reeds, however, have to be voiced carefully, lest the observer should form a wrong judgment through peculiarities of the quality of certain reeds. Besides one must be aware of the tendency to deviate a little from the numerically right intonation, ${ }^{1}$ the cause of which has not yet been made quite clear. Such a tendency, however, is not likely to have affected my observations, because the smallest differences of pitch in the complete scale are considerably greater than the average error caused by that tendency.

All melodies represented by musical notes I shall transpose (if necessary) in certain ways, without regard to the notation (the ' key') used originally by the composer. This transposition causes only a difference in the absolute pitch of the melody, a difference which does not at all concern us here. The reader will see at once that this transposition enables us to use in any example the same musical name for the same number representing the relative pitch.

1 C. Stumpf und M. Meyer, Maassbestimmungen über die Reinheit consonanter Intervalle. Zeitschrift für Psychologie XVIII. , pp. 321-404; and Stumpf's Beiträge zur Akustik und Musikwissenschaft, Heft 2. 
Before I begin the theoretical analysis of complex melodies, I shall give in musical notation with the theoretically corresponding numbers an example of a simple melody, $i$. e., a melody, any tone of which is related to any other tone. Our example is taken from Beethoven's 'Fidelio.'

\section{Beethoven, Fidelio.}

Above the notes are set the theoretically corresponding numbers. According to my method of numeration two different pitches are represented by the number 2 . These pitches represented by the number 2 I shall call 'tonics.' So our melody starts with a tonic, and passes to $3{ }^{1}$ a movement which causes a strong wish to go back to a tonic. This wish is not granted, but the melody passes to a closely related tone 5 , that strengthens the wish to go to a tonic 2. The melody then, indeed, goes over to 2 , but only in order to leave it again and to pass by 5 ,
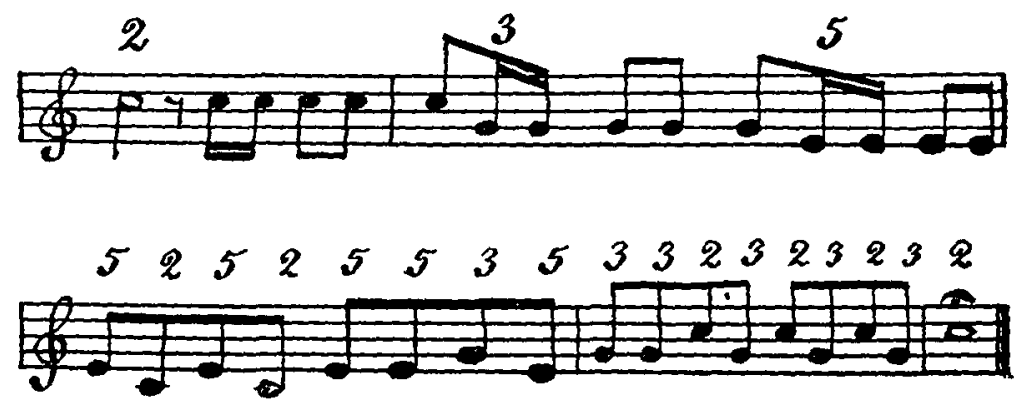

Frg. I.

that causes rather a strong wish to go to a tonic, to 3 , that causes a very strong wish to go to a tonic. However, this wish is not satisfied. The melody passes again to 5 , back to 3 and now to 2. But 2 is left again for a short time and replaced by 3 , whence the melody finally surrenders to 2 . This last movement over 3 back to 2 is repeated twice. 2 has won the battle and the hearer is æsthetically satisfied.

Such a simple melody as that above is not often used in music. It serves, because of its simplicity, very well as a signal, for which, indeed, it is used in Beethoven's opera. A complex

'To this pitch 3 I do not give any name, least of all the name 'dominant,' because such a name cannot be scientifically justified. 
melody is the following tune of Silcher to Uhland's poem ' Der gute Kamerad.'

\section{Silcher, Der gute Kamerad.}

The melody starts with 3. The hearer of course-granted that the melody is unknown to him-cannot guess whether the pitch heard is a tonic or not. From 3 the melody passes to 2. Now the hearer wishes to remain at this pitch. ${ }^{1}$ But the melody passes to 5 and from there to 9 , which is related to 5 and 2, although not very closely. From 5 as well as from 9, more from the former, less from the latter, the hearer wishes to go to 2. This wish is granted, but after some time has passed 2 is left again and is replaced by 3 . For a short moment the melody passes back to 2 and thence to 9 ; from 9 not back to 2 , but to the related tone 5 and from 5 to the related tone 3 . Although 3 is not 2, some rest on 3 causes the hearer a certain amount of satisfaction, because the 9 , which he has met several times, is to 3 as $3: 2$ (according to my numeration). A number like the 3 in this case I call a secondary tonic. From 3 the melody passes to $2 \mathrm{I}$, which is to 3 as $7: 2(i . e ., 3$ appears as a secondary tonic), so that the hearer wishes to go back to 3 . Instead of such a movement the melody passes to 5 , which is closely related to 3 , but not at all to $2 \mathrm{I}$. We shall see that this is very common in music, viz., that the melody instead of passing to a pitch, to which the hearer expects it to pass, passes to another pitch, but one closely related to the expected pitch. Now, with 5 the melody cannot end, because the tonic 2 has been heard already, and in such a case the hearer expects the melody to end with a tonic; otherwise he would not be æsthetically satisfied. After a series of further movements the melody indeed ends with 2 .

We may simplify this melody by reducing it to the relative pitches of that melody of Beethoven, 2, 3 and 5. 'The first part of Silcher's melody is then represented by the numbers 3, $2,5,2,3,2,5,3,5$, forming by themselves an unfinished melody. From the remaining pitches with 3 we get the following

I I hope that no one will raise the objection, that the hearer will probably suppose the melody to be yet unfinished and so will certainly wish to hear the rest. 
melody: $3,9,3,9,3,21,3$. Why I have added to the remaining pitches the last 3 will be seen at once. If we divide each number by 3 , we get $2,3,2,3,2,7,2$, a complete melody with tonics, ending with a tonic (which in the compound melody I call a ' secondary tonic'). This second melody is interwoven with the first one, 3 in both cases being of identical pitch. We have to lay stress on the word 'interwoven,' because in books on musical asthetics we often find an opinion formed, as if a melody were always composed of smaller parts by simply filing
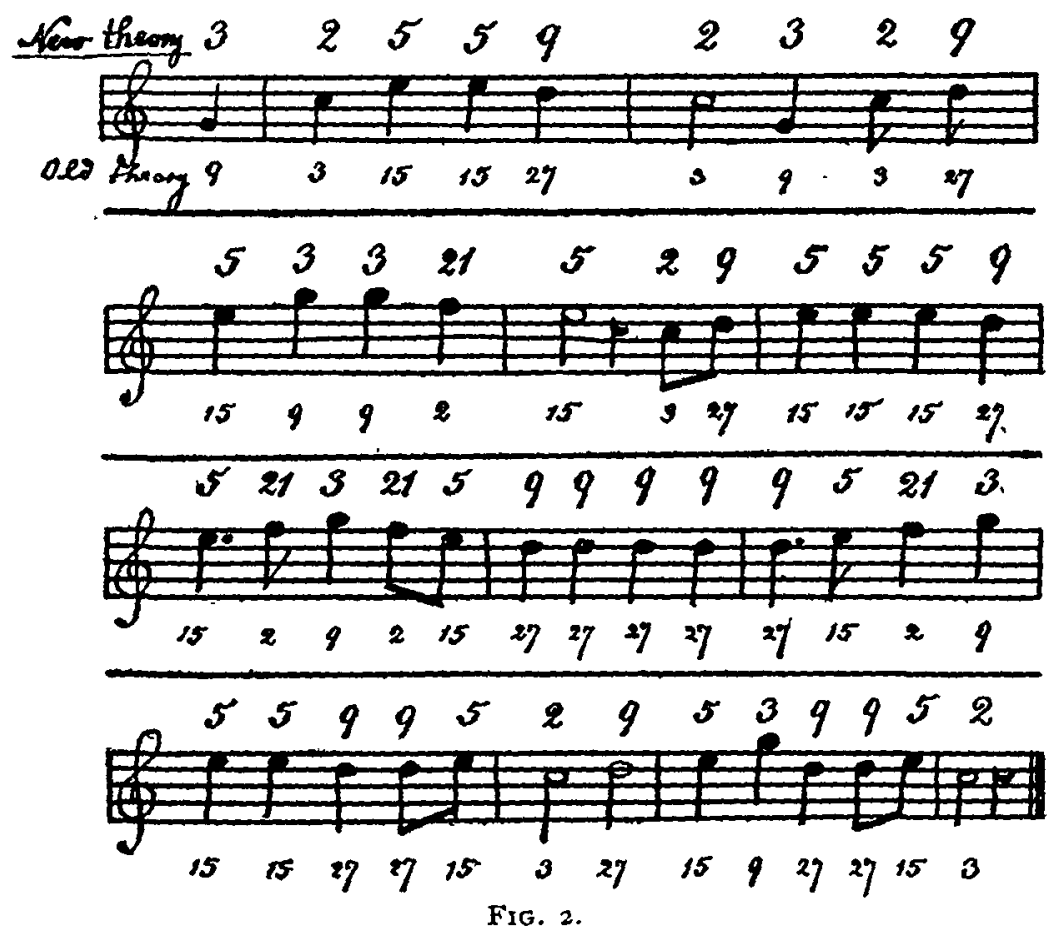

them together. The possible ways of combining melodies such as those above, are of course almost infinite in number, and we cannot discuss all possibilities here. One point only will I mention. I added to the second partial melody the last 3 in order that this melody should end with its tonic. In the compound melody it is not necessary that this last pitch should be really heard; it may be replaced by a closely related pitch (5), which must be a pitch of another partial melody (in our example: 
of that partial melody that carries the tonic of the whole). Similar instances are innumerable in music. We shall see that there is a general law, that the last tone of a partial mclody may be left out, if it can be replaced by a tone closely related to the tone omitted. This however is but a special case of the more general law mentioned on page 255 .

Below the notes in our example II. the numbers are to be found that represent the same melody according to the old theory (Zarlino-Rameau-Helmholtz). Yet here also the powers of 2 are omitted, in order to make the numbers more easily comparable. We notice that in the old theory a pitch is represented by 2 , which is no tonic, but may even be left out entirely without changing greatly the character of the whole. But the tonic itself is represented by 3 , and the melody ends with 3 . According to that theory we have not several partial melodies, one interwoven in a highly artistic way with another; but we have simply a number of pitches, arbitrarily taken from a ' scale' and composed-not into a melody, of course-but into a succession of pitches, in the same manner as a bricklayer builds a wall out of bricks, where it is quite indifferent whether he takes first the one and then the other; or the reverse. When I say ' not into a melody,' I do so, because the most elementary psychological law of melodious succession by that theory is simply neglected, viz., the law, that no hearer is satisfied, if after having heard once or more the tonic 2 he does not find 2 finally at the end of the melody.

When we compare the numbers of the new theory with those of the old one, we see that in the new theory the value of most of the numbers is one-third of that of the numbers of the old theory. In order to compare the intonation corresponding to the numbers of one theory, with the intonation corresponding to the numbers of the other, we may multiply all numbers of the new theory by 3 . Then-in our example II.-the numbers of both theories are identical, except in the case of $f$, which in the new theory is represented by $\sigma_{3}$, in the old theory by 64 . Now, it is easy to make the experiment of playing the same melody with 63 (according to the new theory) and again with 64 (according to the old theory). In the first case the 
melody sounds all right. In the second case the hearer has an impression similar to that experienced when he looks at a painting totally misdrawn. As soon as one hears $2(64)$ he expects this to be a tonic, but his wish to have the melody end with this tone or an octave of it, will never be satisfied. The succession of pitches does not end on the note that appeared by its intonation to be a tonic, but on another one. And this is called ' just intonation' by Helmholtz and his followers.

However, Lipps has gone still farther and pretends to have derived from that ' just intonation' a general psychological law, viz., the law, that from the preceding 2 , the tone 3 becomes ' in a higher degree the proper aim of the movement.' ${ }^{1}$ This is similar to saying of Napoleon: from his previously being emperor, 'Elba' became in a higher degree his proper aim. In order to support his theory Lipps cannot bring forward any argument but the following: "Wenn zwei sich streiten, freut sich der Dritte," 3 in this case being ' the third.' However right this proverb in general may be, it has no place here, because a fight of sensations of tone has never been observed.

One of the errors of the common theory is the presumption, that each note of a melody (save those which only serve to render the music more like 'howling') must have a direct relation to the tonic. Yet the $2 \mathrm{r}$ in our example has no direct relation to the tonic 2. Of course, 2 I could not have been used in this melody but for its relation to 9 and its still closer relation to 3 , which is to $2 I$ as 2 is to 7 . That the note, represented in the new theory by $2 \mathrm{I}$, has no relation to the tonic, has, indeed, always been recognized by unprejudiced musicians. Since the acceptance of Zarlino's diatonic scale they wondered only how this was possible, although the interval was a 'fourth,' represented by the ratio $3: 4$. They did not see that what is called a 'fourth' in music, is not one interval, but several quite different ones, sometimes $3: 4$, sometimes $16: 21$, sometimes still others. We shall see in the following, that music makes extensive use of pitches which have no relation to the tonic, but which, together with one or more pitches related to the tonic, form a partial melody, interwoven with the other partial melody that contains the tonic. 


\section{Beethoven, Das Blümchen Wunderhold,}

The above tune of Beethoven's begins with 3,5,2. Then follows 27 , which has no relation to the preceding tonic 2, although it does have to 3 , the first note of the whole melody. This 27 following 2 affects the hearer like an enigma, because of the lack of relationship. The solution of it is given at once by 9 and 3 , which form a melody with 27 ( 3 being a secondary

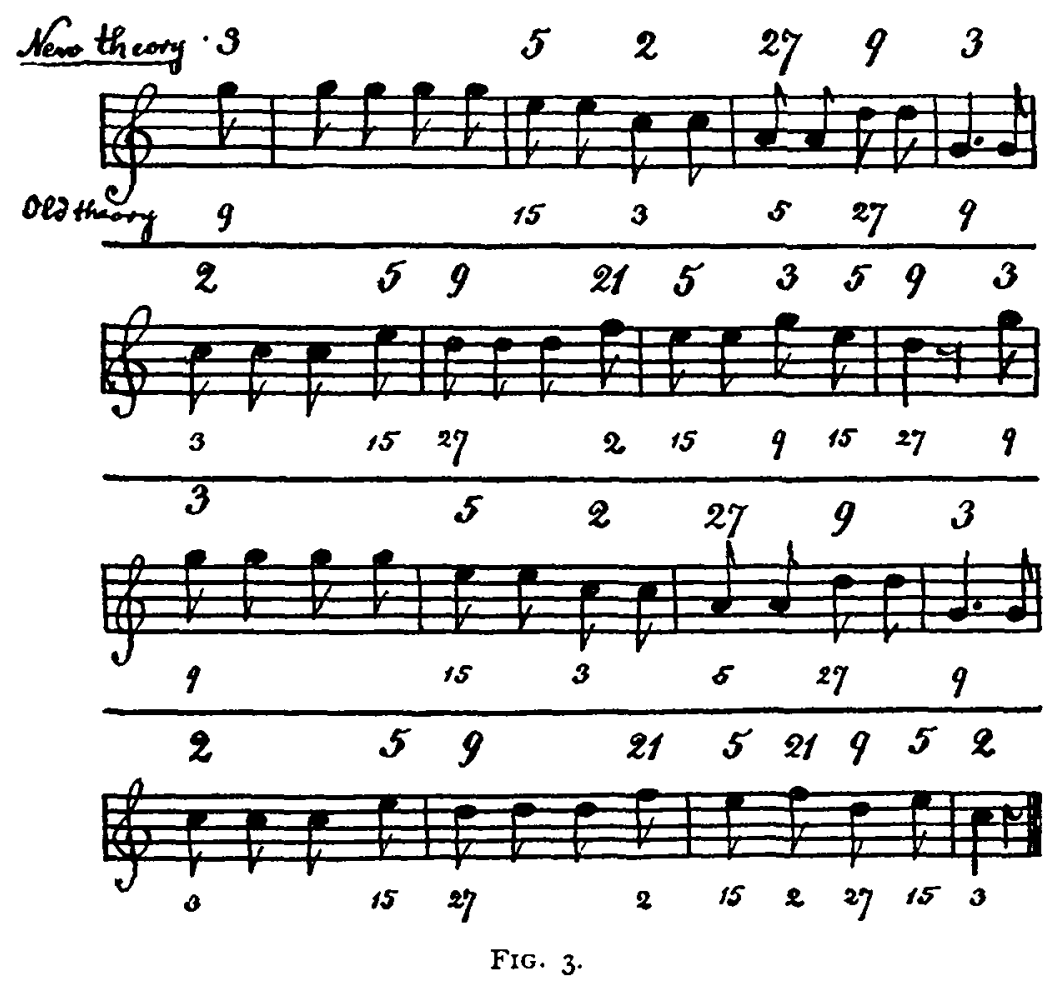

tonic) and which at the same time are closely related to the preceding melody $3,5,2$. A detailed description of the following is scarcely necessary. The reader will find there musical forms similar to those in the previous examples; similar forms, but not exactly the same, for even such a small number of different pitches allows an almost infinite number of melodious combinations. 


\section{IrISh Folk-Song.}

The above melody may be easily analyzed by the reader, except that part where $\mathrm{g}$ \# occurs. Our table shows for $\mathrm{g} \#$ the numbers 25 and 405 . When we play the melody with the one or the other of these tones, we have a decided preference for 405. With the succession of the tones 2, 15, 27, 405, 27, I5, 2 the melody obtains quite a peculiar color. From the first mentioned 2 the melody passes to the related tone ${ }_{5}$, so that the hearer wishes to return to 2 . The melody does not re-

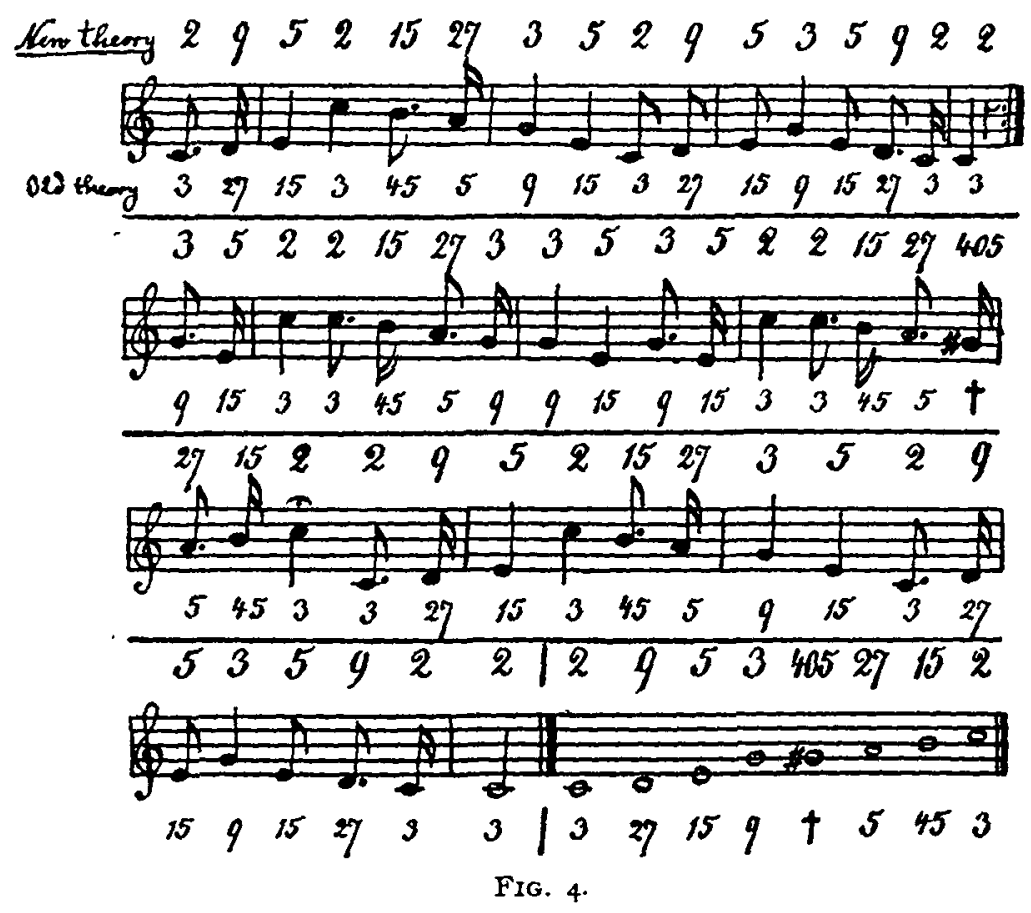

turn, but passes from 15 to the related tone $27(15: 27=5: 9)$, $i$. e., to a tone that has no relation to the expected tone 2 . Moreover, on 27 as a secondary tonic the partial melody 27 , 405,27 (separately $2,15,2$ ) is built up, of which tones none has a relation to 2 . The psychological effect of all this is similar to that of a dangerous situation out of which one sees no way. Yet very soon there appears relief. From 27 the melody passes back again to the related tone ${ }_{5}$, whence it returns to the tonic 2 . 
The melody is followed by the series of tones in musical notation, of which tones it consists. The cross below $\mathrm{g}$ \# means here as in all cases, where it occurs in the following, that the corresponding pitch-according to the old theory-has no relation to the melody, but ' only serves to render the melody more like howling.' A further proof of the worthlessness of that theory is to be found in the fact that this note-as we saw above -has a certain definite intonation, whereas a slight difference of intonation could not have any considerable effect, if the note were only to render the melody ' more like howling.'

A remarkable fact is that this melody contains no 7 .

\section{Mozart, Don Giovanni.}

In this case the melody begins with a tonic, but the first part (four bars) ends with 3 . This would not be remarkable at all in itself, but the way by which the melody arrives at 3 shows

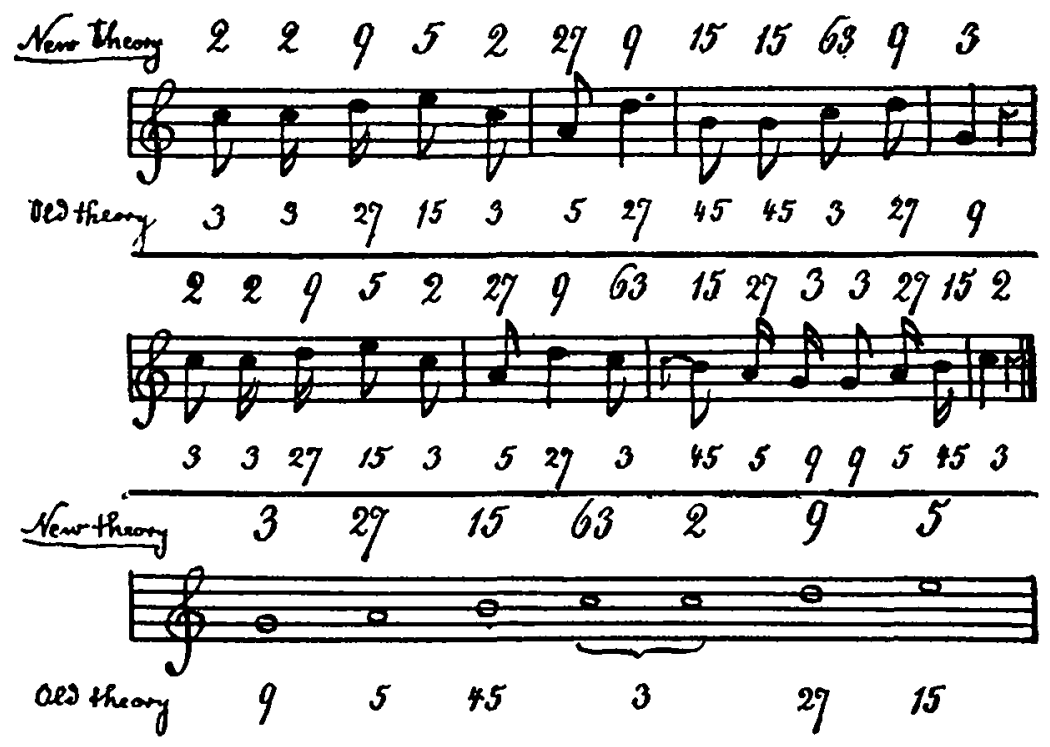

FIG. 5.

that it originated in the mind of a master. From 2 the melody passes to 27 , that has no relation to 2 . This movement affects the hearer in the manner mentioned with example III. After 27 we hear 9, which leads us nearer to the tonic. Now we 
might replace all the notes in the third bar by 9 and so pass directly from 9 to 3 , still nearer to the tonic. Here Mozart introduces the partial melody $\mathrm{I}_{5}, 63,9,3$ (not $\mathrm{I}_{5}, 2,9,3$, as the theory of the diatonic scale supposes), where 3 is a secondary tonic, so that this partial melody separately may be represented by $5,2 \mathrm{I}, 3,2$. That the whole of the first four bars ends with the secondary tonic 3 of a partial melody gives the hearer simultaneously some satisfaction and dissatisfaction: satisfaction, because of the partial melody ending with its tonic ; dissatisfaction, because this part of the whole ends with a strongly accentuated tone, that is not the tonic of the whole, but on the contrary the tone 3 , which causes a particularly strong wish to go to the tonic 2. Now, only, is the final return to the tonic capable of producing the immense æsthetic effect of this melody of Mozart's. The old theory does not tell us anything of all this. According to that theory, the whole beauty is caused simply by the pitches being taken from the diatonic scale. Then indeed it is difficult to understand why other melodies, the tones of which are also taken from that scale, are not just as beautiful.

\section{Beethoven, Sonata, Op. I4, No. 2.}

The first part $3,3,75,5,15,2$ of this melody ends with a tonic. It contains the partial melody $75,5(15,2)$ with 5 as a secondary tonic. The second pari is a partial melody (separately represented by the numbers $3,3,9,75,15,2$ ), built up on 9 as a secondary tonic. This partial melody itself has to be analyzed again, the melody 675, I 35 (separately 5, 2) being a partial melody with 135 as a secondary tonic. The old theory represents the second part of Beethoven's melody by 5, 5, 15, $2, \uparrow, 27$.

In the third part the melody, passing through a number of smaller partial melodies, touches 2 several times and finally closes with 2 . The last notes are $3,21,15,2$. There we may question why the 3 above the 2 has been used and not the 3 below the 2. Some theorists have alleged that the mere movement of ascent and descent of the pitches, even without any relationship, is an important factor of the æsthetic effect of music. It 
is possible, indeed, that ascent and descent have a slight æsthetic effect. However, I have not observed this effect myself nor has any one else, and so I must regard its alleged importance as lacking any proof. What I have observed, is the following: Suppose the composer intends to form a melody of two different tones, one of which is absolutely given, e.g., 2 in a certain pitch, but the other is determined only by its number, e. $g ., 3$,

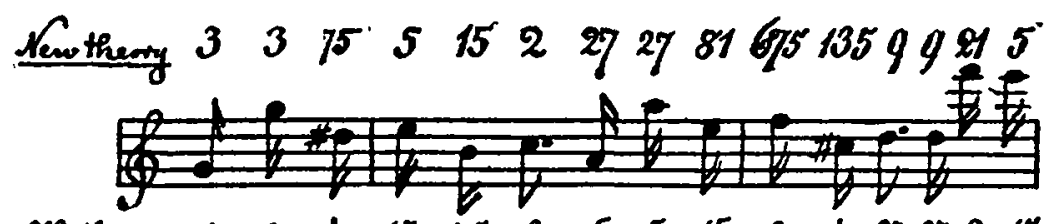

ols theory $99+1545355152+2927215$

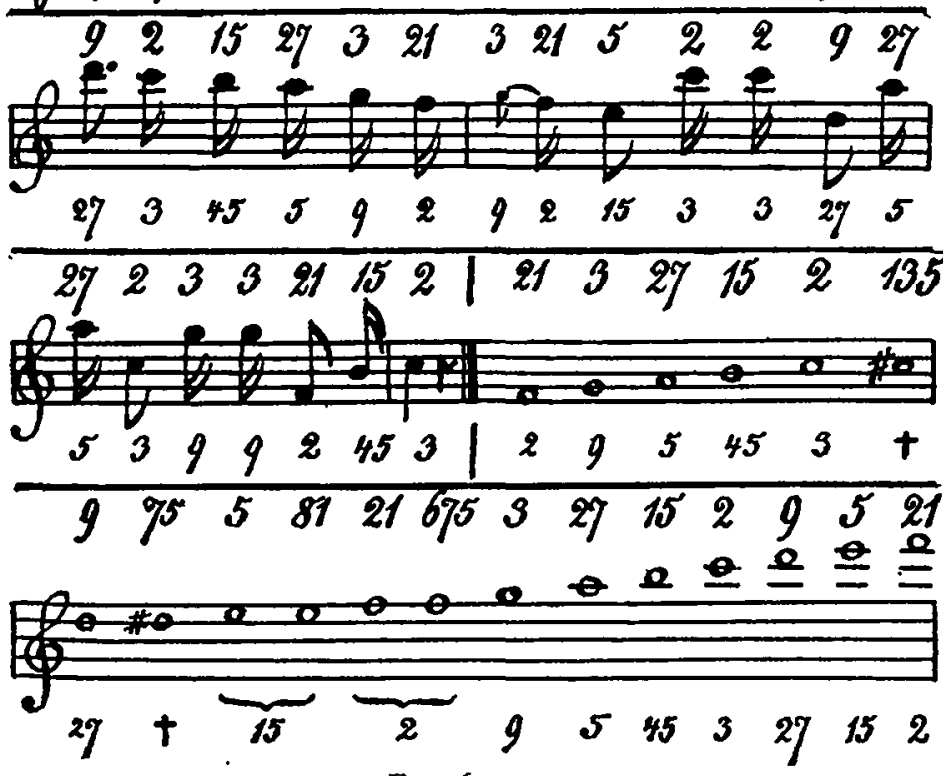

Fig. 6.

so that several pitches, differing by the interval of an octave, are possible. In such a case, if there is no particular purpose, that 3 is used which is nearest the given $2, i$. e., the 3 below. Yet when not only the 2 is given, but another tone too, e.g., the 5 just above the 2 , and 3 (without determined pitch) has to be added, that 3 is added which is nearest both given tones; i.e., the 3 above the 2 is added. When in this latter case the 3 below 
2 is used, the melodious unit of the three tones 2,5 and 3 is solved and two partial melodies (composed of 2 and 3 and of 2 and 5), interwoven with each other, are the result. When the composer desires a complex form, he has to use in this case the 3 below, when he desires a simple form, the 3 above.

If Beethoven at the end of the present melody had used the 3 below the I, the whole of the last four notes would act upon us as a combination of the two partial melodies $3,15,2$, and 3 , $2 \mathrm{I}, 3$, the latter interwoven into the former. But in the present form the last four notes act upon us as a combination of the partial melodies 3,2 , and $21,15,2$, because 3 by the greater distance has been severed from $x 5$ and 21 . The second partial melody $2 \mathrm{I}, \mathrm{I5}, 2$ in this case is again composed of two partial melodies, viz., 21,15 (separately 7,5 ), and $x_{5}, 2$, so that, by this use of the 3 above, the whole form of these four notes has been changed.

Another case of this kind is the separation of the 21 from the preceding 9 in the third bar. The 2 I forms a partial melody with the following 9 of the fourth bar.

Gurney says in his 'Power of Sound': " the ascent from the dominant to the tonic above, the descent to the tonic below, each seeming right in its place, while in a form that was worth anything either would be resented as a substitute for the other." We have seen above that this fact is not so wonderful and beyond human understanding as Gurney assumes it to be. Of course, it is not impossible to exchange a 3 or any tone of another number for an octave of it; yet in some cases the melody ends better with a simpler, in others better with a more complex form.

\section{Beethoven, 4. Symphony.}

In the above melody I wish to call the reader's attention to the melodious form $5,45,45,3,25$ of the third and fourth bars, which form, according to the old theory, would be nothing more than 'howling.' This form has to be regarded as composed of the melodies $5,45,3$ and 45,25 (separately 9, 5). The following 27 is then connected with this form by the relation of 27 to 3 . I have tried on the organ above mentioned to 
find whether in the case of $\mathrm{g} \# 25$ is right, or 405 , which with the following 27 would form a melody (separately the melody

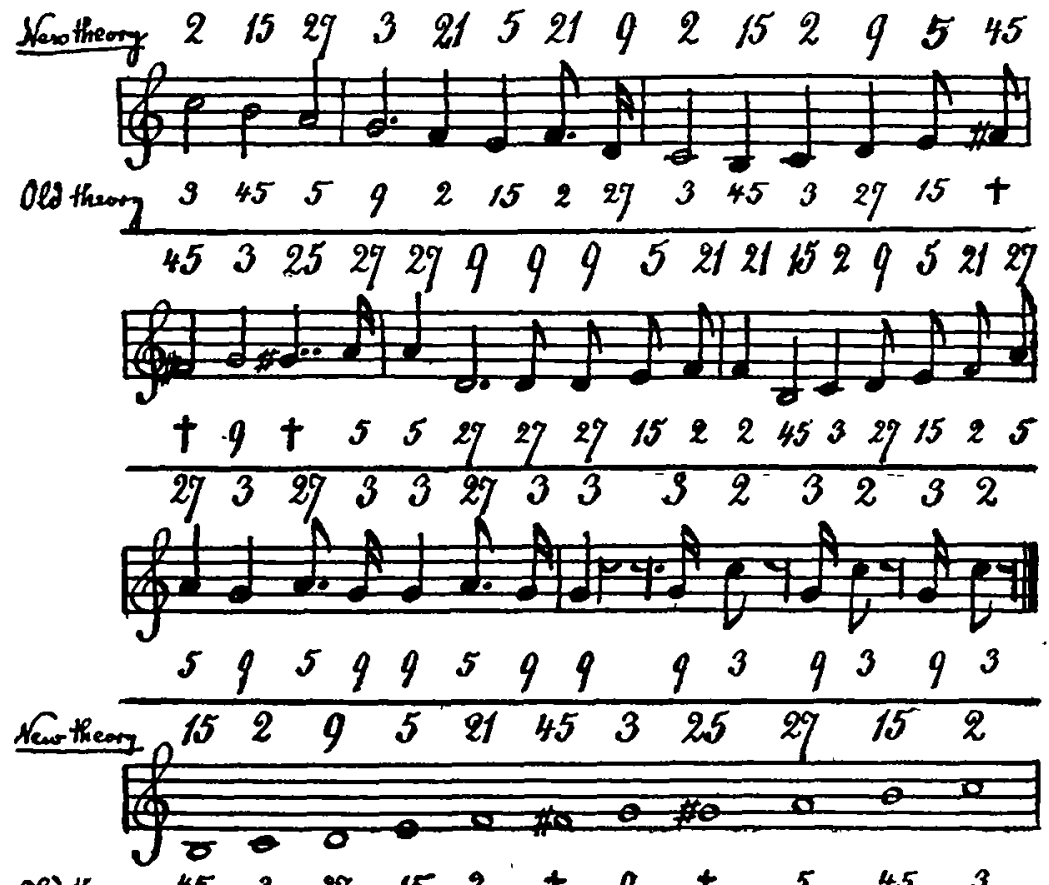

oes thang $45327152+9+5453$

FIg. 7 .

I5, 2). 25 appears to me to yield a better æsthetic effect than 405 .

\section{Beethoven, 6. Symphony.}

The first part of this melody is a partial melody (separately represented by the numbers $2,3,5,2,3,5,2,3,5,2,3,2$ ) with 27 as a secondary tonic. The second part is a partial melody (separately $3,2,2,3,2,2,3,2$ ) with 9 as a secondary tonic, so that the movement from the first secondary tonic to the second is identical with a passage from a 3 to a 2 . The next partial melody $9,15,9,9$ (separately $3,5,3,3$ ) is a melody without a tonic. From this we arrive at the last part, which contains the primary tonic 2. The first three bars of this part are composed very simply of 2,3 and 5 . Three times the 
melody touches 2; but when 2 is expected again for the fourth time, $2 I$ is heard, which has no relation to 2 . The psychological effect of such a movement has already been mentioned. Yet $2 I$ is followed by 9 , which is related to $2 I$ as well as to 2 . This melody of Beethoven's is an excellent example for those

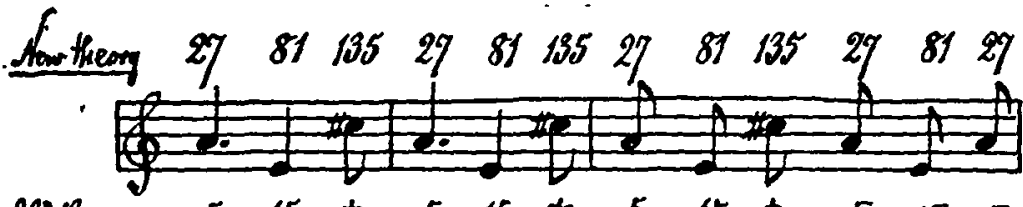

De8theory $515+515+515+5155$

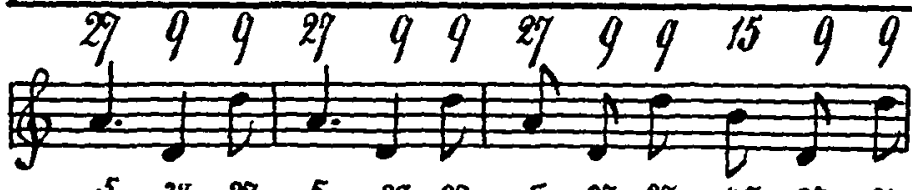

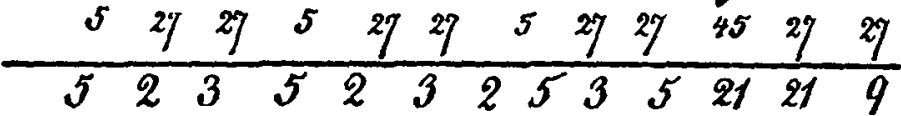

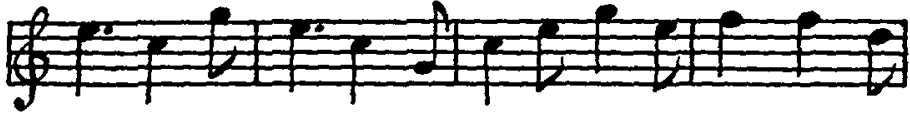

$\begin{array}{llllllllllllll}15 & 3 & 9 & 15 & 3 & 9 & 3 & 15 & 4 & 15 & 2 & 2 & 27\end{array}$

2193355259929153328

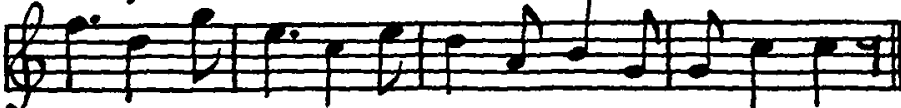

$\begin{array}{llllllllllllll}2 & 27 & 9 & 15 & 3 & 15 & 29 & 5 & 45 & 9 & 9 & 3 & 3\end{array}$

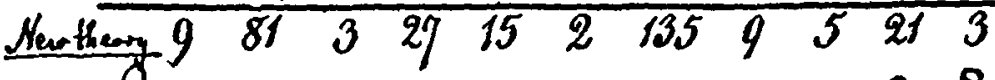

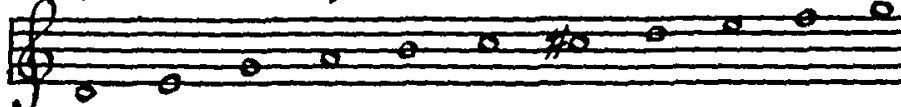

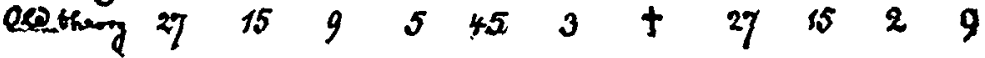

FIG. 8.

readers who wish to convince themselves of the truth. I can only advise them to play this melody in the intonation corresponding to the new theory and to compare it played in Helmholtz's 'just intonation,' which-when the hearer is aware of the intonation-annihilates the whole æsthetic effect. 
IX. Schubert, Heidenröslein.

Schubert's 'Heidenröslein' is a very complex piece of music. The first part is a comparatively simple melody, which ends with a tonic. The next part contains 9 as a secondary tonic and is separately identical with $9,21,5,9,2$. The third part contains 3 as a secondary tonic and is separately identical with

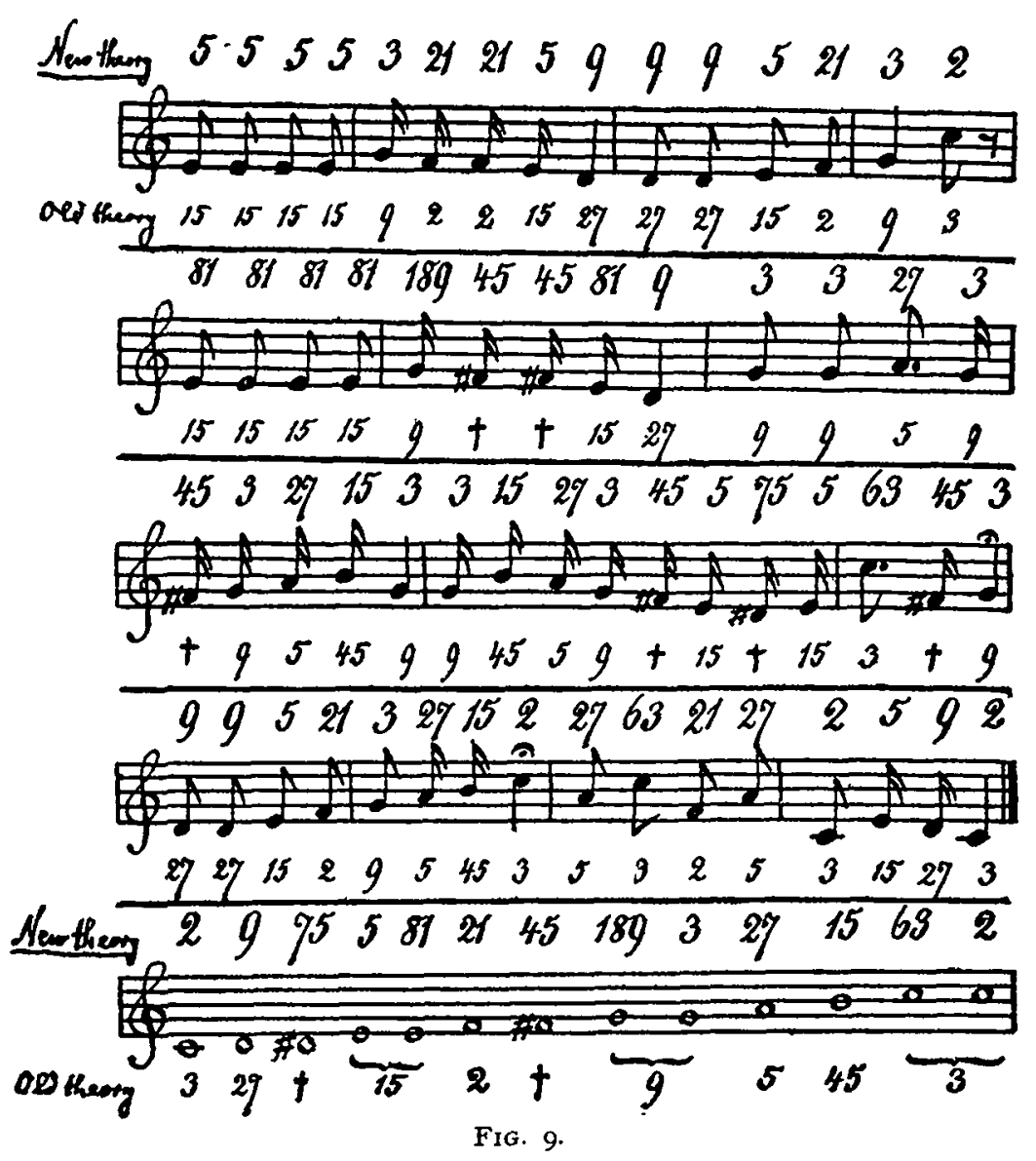

$2,9,2, x_{5}, 2,9,5,2$. This 3 , the secondary tonic of the third part, is to the primary tonic 2 in closer relation than in the previous secondary tonic 9 , so that after having left the primary tonic 2 for 9 , the secondary tonic of the second part, we gradually approach the 2 again. The fourth part is a melody with- 
out a tonic, but begins and ends with 3 , so that it is closely related to the third and fifth parts. The fifth part leads back to a tonic 2. The sixth part begins with some tones not related to 2 , which remind us of the second, third and fourth parts of the whole melody. These tones are connected with the final tonic by means of the following 9 . The old theory, of course, cannot tell us whence originates the extraordinary æsthetic effect of this comparatively brief song. The old theory is unable to detect the complexity of form of this melody, which distinguishes it from trivial melodies, the simple forms of which, heard a thousand times, we get tired of.

Yet for a song that is really so complex as this one of Schubert's, the accompaniment is of great importance. I have found indeed that people, who were not sufficiently trained to pay attention to the accompaniment, did not appreciate the æsthetic value of Schubert's song. However, this paper being devoted to melody only, I will not go into discussion of the harmonies. I hope I shall be able to publish my investigations into harmony soon in another paper.

We shall analyze now a second, rather different class of melodies, viz., melodies without a tonic. Instances of such melodies have been found already in some partial melodies within the preceding examples. In this second class of music we find many instances of partial melodies containing a secondary tonic, but we do not find any primary tonic 2 .

\section{German Choral.}

In this melody there is no pure power of $2, i$. e., no primary tonic according to our definition of a tonic. But there are secondary tonics. The melody has been harmonically treated indeed, by musicians, as if 63 were a tonic (identified with 64). However the æsthetic effect of the melody itself is destroyed by this, although I will not deny that many a hearer in spite of the destruction of the melody may be much pleased by the successions of harmonies offered by the composer instead of the melody. 
PSYCHOLOGICAL THEORY OF MELODY.

1559631529154533455455 \%

345954599959636315 \% 1590

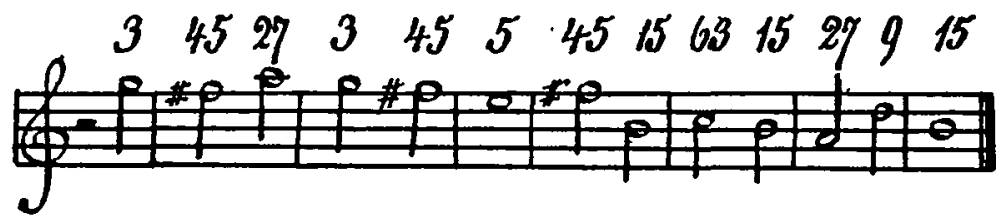

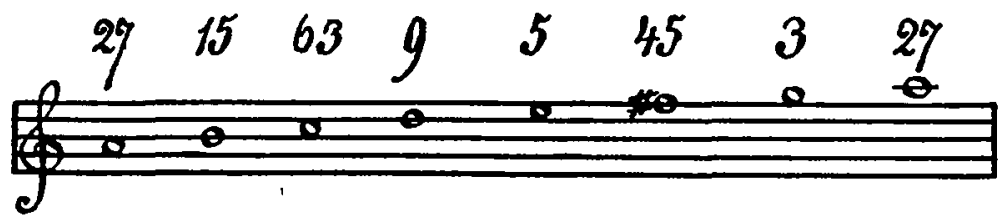
FIG. IO.

$\begin{array}{llllllllllllll}15 & 5 & 453 & 15 & 15 & 5 & 15 & 5 & 45 & 3 & 15 & 15 & 5 & 5\end{array}$

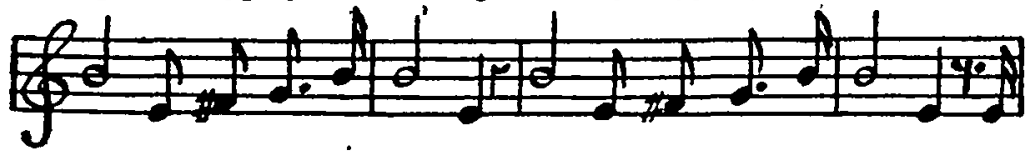

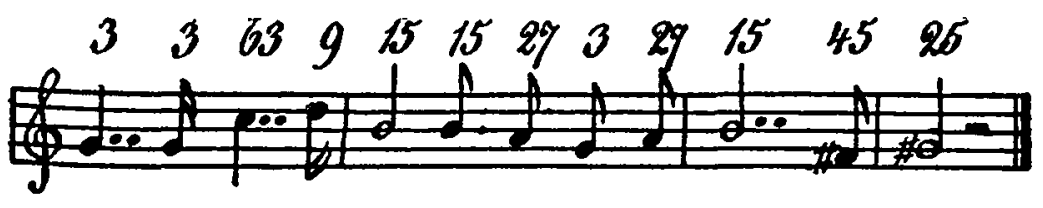

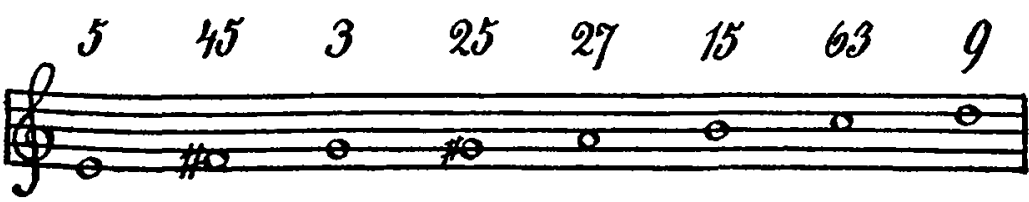

FIG. II. 


\section{WAGNer, LOHENGRIN.}

The above well known melody from Wagner's Lohengrin is another example of a melody without a (primary) tonic. This melody ends with 25. The previous melody ends with 15 . We shall find other melodies end with still other numbers. There is not such a law, that a melody without a tonic must inevitably end with a certain number, as in the case of a melody with one (or more than one) tonic, where the last note of the melody must be a tonic.

\section{Old German Song.}

This melody ends with 5. The old theory, which calls the last note of any melody the 'tonic' or 'key note' -although there is no complete agreement on this matter-would regard 5 to be the key note in this case; and since the Major Third (25) of 5 does not appear in the melody, but the Minor Third (3)
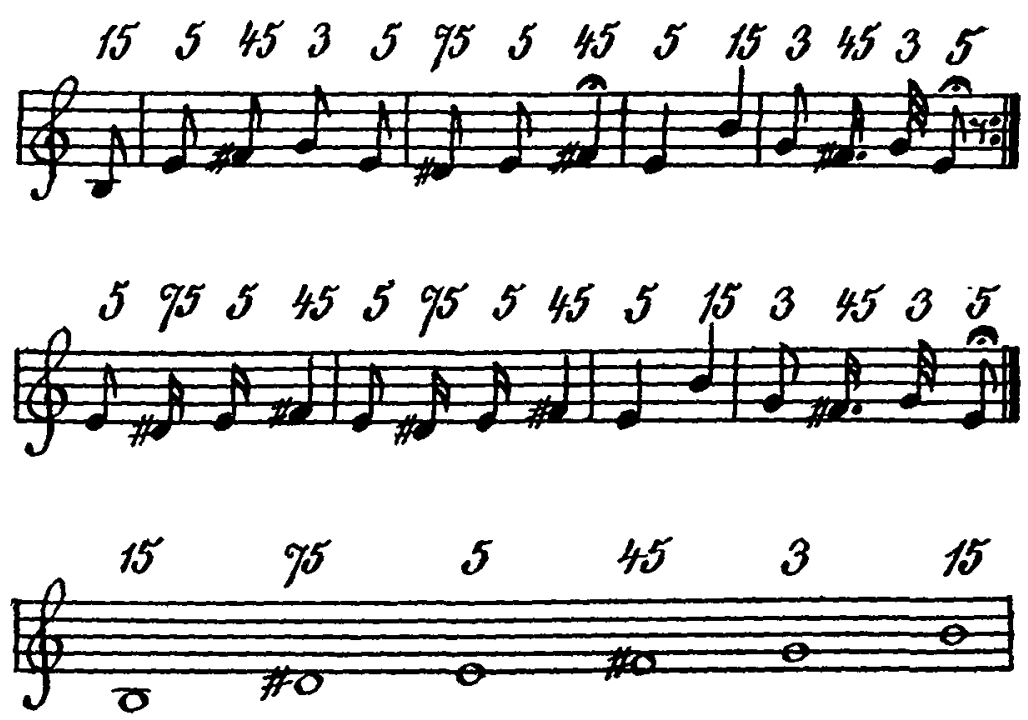

Fig. 12.

does, the old theory would say that this melody is a melody 'in minor.' Now, according to the theory mentioned above, which Herzogenberg has brought forward, the interval of the Minor Third of the key note would have to be represented by $3: 7$. The whole melody then would be represented by the fol- 
lowing numbers: $27,9,5,21,9,135,9,5,9,27,21,5,21,9$, $9,135,9,5,9,135,9,5,9,27,21,5,21,9$. I have tried in this case as well as in others the intonation corresponding to Herzogenberg's theory. The result of this examination is, that I have no doubt that Herzogenberg's theory in general is wrong.

\section{Lithuanian Folk Song.}

I tried first to represent the above melody by numbers in such a manner that the last note corresponds to 2. Yet the melody sounds out of tune in that intonation. The intonation that corresponds to the above numbers appears to me to be the right one. So this melody proves to be a melody without a tonic, ending with 9 .

How the lack of a primary tonic in the melodies of the second class, the want of a tonal basis at the end of the melody,
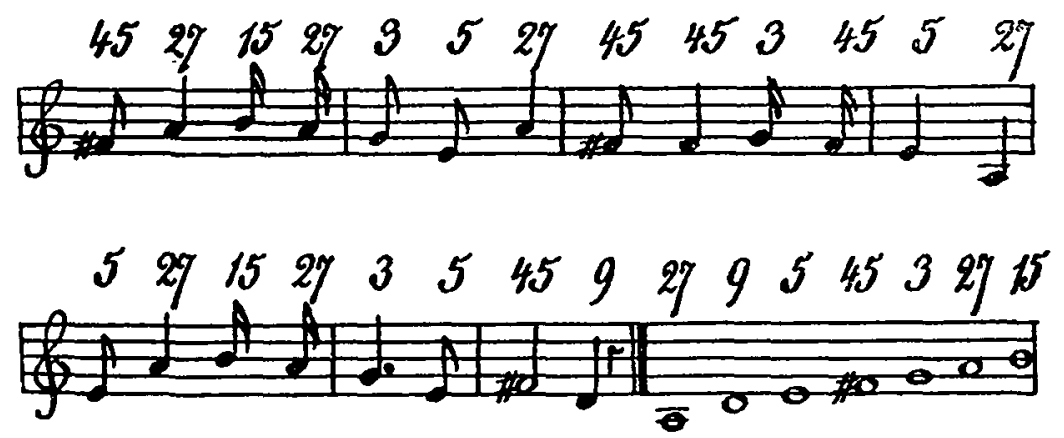

FIG. 13.

acts upon the hearer, is well known by every music lover. This peculiarity of the æsthetic effect of these melodies is readily understood from our theory. It cannot be understood from the old theory.

I regret that I cannot add to these examples an Arabian melody containing a 'quarter tone.' Many Arabian 'scales' with a quarter tone are to be found in different books. Yet these scales are worthless for the science of music. I have been unable to detect any real melody containing a quarter tone, although there is no doubt that such melodies are used in the Orient. According to my theory there is nothing wonderful in the fact of a quarter tone in a melody. $E$. $g$., a melody built up of the 
tones $35,9,5,2 \mathrm{I}$ may contain a 'quarter tone' of the interval $35: 36$.

\section{SUMMARY.}

I. When we hear a succession of different pitches we are affected in a certain way, which cannot be described, but has to be regarded as an elementary psychological fact. We may express this fact by saying: we observe with different ratios of the vibration rates a different relationship of two successive pitches; in certain cases we observe no relationship at all.

2. We call the relationship close when the ratio of the vibration rates consists of small numbers; remote, when the ratio consists of large numbers. In this respect, however, we should bear in mind that any power of 2 has an exceptional position.

3. The order of relationship within the series of related pitches seems to be the following (using my numeration above described) : $2-2,2-3,2-5,3-5,2-7,3-7,2-9,2-15,5-7,5-9$. Whether there is a slight degree of relationship in the cases of $7-9$ and $7-15$, or no relationship at all, I do not venture to decide. Neither do I assert that the series above represents an accurate order of the relationships. In all other combinations of the powers of $2,3,5$ and 7 there is only an indirect relationship by mediation of a third tone, so that we have to dissolve the melody into partial melodies.

4. No relationship-as far as I know-has ever been observed by any human being in the case of prime numbers higher than 7, as II, I3, I7, I9, etc. Relationship is to be observed only with pitches represented by the relative numbers 2 , 3, 5, 7 and their composites.

5. When of two different pitches forming a melody one corresponds to a pure power of 2 and the other to one of the numbers $3,5,7,9,15$ (neglecting all powers of 2), we wish to hear 2 at the end of the melody, and we are æsthetically dissatisfied until our wish is granted. The power of 2 in such a case we may call 'tonic.'

6. All melodies, simple or complex, are to be divided into two classes, those with a tonic and those without a tonic. 
7. Complex melodies, as commonly used in music, may be composed of simple melodies either by simply filing them together or by more or less artistically interweaving them into each other.

8. Very common in music is the particular æsthetic effect produced by the following movement: The melody instead of passing to a pitch to which the hearer expects it to pass, passes to another pitch, but one closely related to the expected pitch. A special case of this movement is: the last tone of a partial melody being left out and replaced by a related tone.

9. Of all tones ('octaves') that have a certain relation, aimed at by the composer, to a given tone, that tone is used which is nearest the given tone. The effect of another 'octave' being used is : the change of a simple melody into a complex one.

Io. The 'quarter tones' of the Arabs are no exception to the general psychological laws of melody.

II. No observation has been made that would justify the exclusion from the theory of music of the number 7 . On the contrary, observation proves that the exclusion of the 7 is impossible.

I2. The musical terms 'Major,' ' Minor,' ' Dominant,' ' SubDominant,' have only a historic, no scientific value. Neither have the ancient and modern 'scales' any scientific value. 